\title{
Validation study of the Arabic version of the Brief Fatigue Inventory (BFI-A)
}

Khaled Suleiman, ${ }^{1}$ Mahmoud Al Kalaldeh, ${ }^{1}$ Loai AbuSharour, ${ }^{1}$ Bernice Yates, ${ }^{2}$ Ann Berger, ${ }^{2}$ Tito Mendoza, ${ }^{3}$ Malakeh Malak, ${ }^{1}$ Ayman Bani Salameh, ${ }^{1}$ Charles Cleeland ${ }^{3}$ and Ahmed Menshawi ${ }^{4}$

${ }^{1}$ School of Nursing, Al-Zaytoonah University of Jordan, Amman, Jordan (Correspondence to: K. Suleiman: ksuleiman@zuj.edu.jo). ${ }^{2}$ College of Nursing, University of Nebraska Medical Centre, Omaha, United States of America. ${ }^{3}$ MD Anderson Cancer Center, Houston, United States of America. ${ }^{4}$ King Hussein Cancer Center, Amman, Jordan.

\begin{abstract}
Background: Fatigue is the most reported and most distressing symptom among patients with cancer. However, no questionnaire that measures fatigue and fatigue interference with life has been translated into Arabic.

Aims: This study aimed to translate and validate the Arabic version of the Brief Fatigue Inventory (BFI-A).

Methods: The BFI was translated into Arabic using the forward-backward translation technique. This cross-sectional study collected data from cancer patients through a self-administered questionnaire that included the BFI-A, Insomnia Severity Index (ISI), Zung Depression Scale (ZDS), MD Anderson Symptom Inventory total score (MDASI), and Medical Outcome Study Short Form 36 (SF-36) Vitality Subscale. Descriptive and inferential statistics were used including mean, standard deviation, internal consistency, and correlation coefficient using Pearson's correlation.

Results: A total of 79 patients were recruited in Amman, Jordan, in 2015. Mean of the total BFI-A was 4.01 (2.4), showing that $83.5 \%$ had nonsevere fatigue. Cronbach's $\alpha$ coefficient of the BFI-A was 0.93. The correlations between total BFI-A scores and BFI-A items were significant $(P<0.05)$ and ranged from 0.75 to 0.86 . BFI-A showed a significant correlation $(P<$ 0.05) with the following tools: ISI $=0.70, \mathrm{ZDS}=0.69, \mathrm{MDASI}=0.75$, and SF-36 Vitality Subscale $=-0.57$.

Conclusions: This study suggests that the BFI-A is a reliable and valid tool to assess fatigue among Arab cancer patients. Keywords: Arabic, cancer, fatigue, validation.

Citation: Suleiman K; Al Kalaldeh M; Shahroor LA; Yates B; Berger A; Mendoza T; et al. Validation study of the Arabic version of the Brief Fatigue Inventory (BFI-A). East Mediterr Health J. 2019;25(11):784-790. https://doi.org/10.26719/emhj.19.032

Received: 19/10/16; accepted: 30/01/18

Copyright (C) World Health Organization (WHO) 2019. Some rights reserved. This work is available under the CC BY-NC-SA 3.o IGO license https:// creativecommons.org/licenses/by-nc-sa/3.0/igo
\end{abstract}

\section{Introduction}

Fatigue is the most frequent and distressing symptom reported by patients with cancer (1). In addition, fatigue reduces functional status (2), social functioning and quality of life (3). Patients with cancer experience fatigue as a multidimensional, subjective feeling of physical, emotional and cognitive exhaustion that is not relieved by rest (4). Fatigue is contributed to by the disease process itself and during and after treatment such as chemotherapy and radiotherapy (5). Fatigue is experienced with other symptoms such as insomnia (6) and depression (7).

Many instruments have been constructed to measure fatigue. Some of these instruments are long and time consuming, while others include expressions or idioms that are hard to translate into another language (8). The Brief Fatigue Inventory (BFI) (8) is one of the most widely used measures of fatigue among patients with cancer. The BFI assesses severity of fatigue and the interference of fatigue with daily functioning in the past 24 hours. The BFI was developed to be a brief screening measure of fatigue among patients with cancer that is easy to comprehend, score and translate into other languages. The BFI is a reliable and valid tool that has been used to measure fatigue among different cancer populations such as lung and breast cancer $(7,9)$.
The BFI has been translated into other languages including German (10), Greek (9), Italian (3), Japanese (2), Chinese (5) and Taiwanese (11). The translated versions of the BFI have demonstrated acceptable internal consistency reliability for a newly translated tool for cancer patients. The reliability ranges from 0.92 for the German (10) and Chinese (5) versions to 0.96 for the Japanese (2) and Taiwanese (11) versions. An Arabic translation of the BFI will provide a standardized fatigue questionnaire for Arab researchers to investigate the subjective aspects of fatigue among Arab patients with cancer. Most of the investigators who translated the BFI into other languages used the backtranslation method $(2,3,5,9)$, which involves translation (from source to target language) and back-translation (to source language) using independent translators at each step (12). Also, the majority of investigators used selfreport measures to examine convergent validity between the newly translated measure and other fatigue measures or other concepts related to fatigue such as depression or vitality $(2,3,5,9)$.

Little is known about fatigue among Arab patients with cancer. This is mainly due to the lack of Arabic instruments that measure fatigue. Currently, the Chandler Fatigue Scale (CFS) (13) is the only instrument that has been translated into Arabic (14). The CFS is hard to score and does not measure the impact of fatigue on 
daily functioning. In addition, it was not constructed to measure fatigue specifically among patients with cancer. Only 2 studies have examined fatigue among the Arab population $(14,15)$. In these studies, fatigue was measured using the CFS. In the first study, the researchers validated the CFS (14). The internal consistency reliability of the CFS was 0.74. They also reported significant inter-rater reliability. Additionally, for criterion validity purposes, no significant differences were found between the Arabic and English versions of the CFS in 46 bilingual students (14). In another study testing the CFS in Arabic, no psychometric information was reported (15).

An additional measure of fatigue in the Arabic language is needed that captures the impact of cancer on patients' daily lives and detects the effects of interventions designed to improve fatigue and daily functioning in Arab patients with cancer. In addition, measuring fatigue using an Arabic version of the BFI will provide the opportunity to measure fatigue crossculturally among different Arab populations with cancer. Thus, the aims of this study were 1) to translate the BFI into Arabic (Fusha dialect), which is the education dialect in all Arab countries; and 2) to obtain psychometric data including convergent validity and internal consistency reliability for the newly translated tool.

\section{Methods}

\section{Instrument translation}

The final version of the BFI-A (Figure 1) in this study was obtained by the back-translation method (12). The translation process started by translating the English version of the BFI into Arabic by a bilingual Arabic translator. A second bilingual Arab researcher then blindly back-translated the Arabic version of the BFI into English. Finally, the back-translated version and the original BFI version were compared for equivalence by a monolingual English speaker with a $\mathrm{PhD}$ in nursing (fourth author). Vocabulary equivalence reflects the meaning and the nuances of the original terms compared to words selected for the translated tool (16). There are 2 words for fatigue in Arabic: "tiredness" and "exhaustion". By consensus among the translators, the term "tiredness" was chosen to represent fatigue as it more closely reflects the nuances of the word fatigue in Arabic.

\section{Sample and setting}

This was a cross-sectional study with descriptive and correlational elements to translate the BFI into Arabic. A convenience sample of 79 patients with cancer was recruited from an outpatient oncology clinic at King Hussein Cancer Center in Amman, Jordan. The inclusion criteria were: men and women aged $\geq 18$ years; ability to read and write in Arabic; and diagnosed with any type of cancer. Patients who could not understand the intent of the study or were unable to give consent were excluded.

Ethical approval was obtained from the Institutional Review Board of the King Hussein Cancer Center and

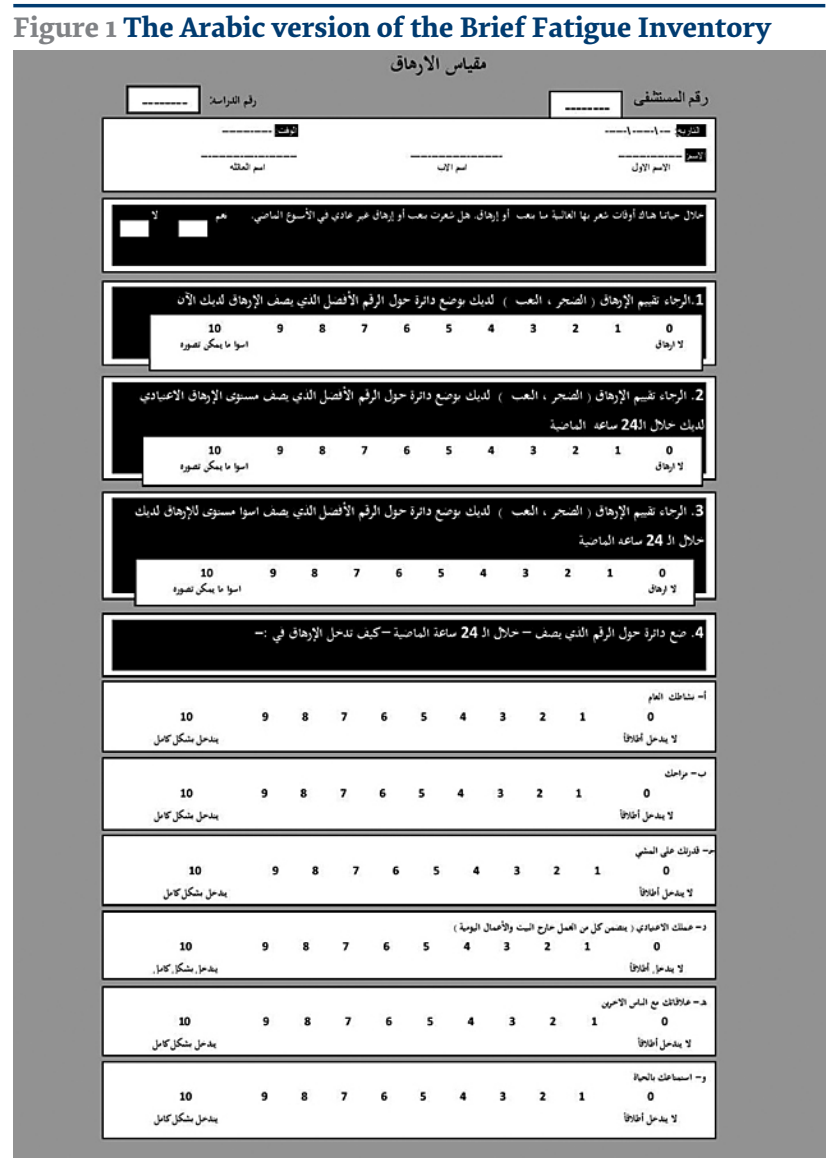

Al-Zaytoonah University of Jordan. Participants were recruited through direct contact with the investigators at King Hussein Cancer Center. The participants were asked to complete the questionnaires during their visit to the outpatient oncology clinic. The study purpose and objectives were explained to the participants and they were informed that their return of the questionnaires constituted consent. The investigators reassured participants that they had the right to withdraw from the study at any time and that the data would be confidential.

\section{Instruments comparison}

A questionnaire package was administered to the participants that included a demographic sheet, the translated BFI, and 4 measures in Arabic for convergent validity purposes. These measures were the Insomnia Severity Index (ISI) (17), Zung Depression Scale (ZDS) (18), MD Anderson Symptom Inventory (MDASI) (19), and the Vitality Subscale from the Medical Outcomes Study Short Form36 (SF-36) (20). Expectation was that the ISI, ZDS and the MDASI would correlate positively with the BFI and the Vitality Subscale would correlate negatively with the BFI.

\section{BFI}

The BFI (8) is a 9-item scale that measures fatigue severity and interference with life on an 11-point scale for the past 24 hours. The total score for the BFI can be obtained by averaging all 9 items and can range from 0 to 10; with a higher score indicating more fatigue and more fatigue interference with life. The first 3 items ask patients to rate 
the severity of their fatigue now, at its usual level, and its worst level ranging from o (no fatigue) to 10 (fatigue as bad as you can imagine). The next 6 items measure fatigue interference with patient's life including general activity, mood, walking ability, normal work, relationships with other people, and enjoyment of life. Interference is rated on a $0-10$ scale with $0=$ "does not interfere" and $10=$ "completely interferes". Mendoza et al. (8) set up cut-points for fatigue severity: a rating of o-6 indicating "non-severe" and $\geq 7$ indicating "severe". They reported that the BFI had a high internal consistency coefficient of 0.96 . The validity of the BFI was supported by significant correlations with both the Functional Assessment of Cancer Therapy-Fatigue scale $(r=-0.88, P<0.001)$ and the Profile of Mood States-Vigor $(r=-0.84, P<0.001)(8)$.

\section{ISI}

The ISI (17) measures the severity of insomnia using 7 items for the past 2 weeks. Each item ranges from o (not at all severe) to 4 (very severe) with the total score ranging from o to 28. Higher scores denote greater insomnia severity. The ISI demonstrated high internal consistency of 0.88 (17) and good convergent validity with sleep diary indices (correlations ranging from 0.32 to 0.91 , $P<0.05)(21)$. Suleiman and Yates (22) reported high internal consistency $(\alpha=0.84)$ among Arab participants when translating the ISI into Arabic.

\section{ZDS}

The ZDS (18) is a 20 item self-report measure of depression for the past week. Each item is scored with a 4-point scale ranging from 1 to 4 (a little of the time, some of the time, good part of the time, and most of the time). The total scale ranges from 20 to 80 . The authors of the original scale set cut-points for the level of depression as follows: 20-49 normal range; 50-59 mildly depressed; 60-69 moderately depressed; and $\geq 70$ severely depressed. Of the 20 items, 10 are worded positively and 10 are worded negatively. The validity and the reliability of the scale have been established (23). Among several physicians and Arabic-speaking linguistic experts, Kirkby et al. (24) found substantial agreement between the scores obtained when comparing the Arabic and English versions of ZDS. The $\kappa$ measurement of agreement was 0.65 ( $95 \%$ confidence interval $0.57-0.73$ ).

\section{MDASI}

The MDASI (19) consists of 19 items. The first 13 items assess severity of 13 cancer-related symptoms on a 0-10 scale $(0=$ "not present" and $10=$ "as bad as you can imagine") over the past 24 hours. Another 6 items assess the interference of these symptoms with daily living on a $0-10$ scale ( 0 = "did not interfere" to $10=$ "completely interferes") over the past 24 hours. The 13 symptom severity items of the MDASI can be averaged into a symptom subscale score and the 6 interference items can be averaged into an interference subscale score. The MDASI demonstrated an internal consistency reliability of 0.85 for the general symptom severity items, and 0.91 for the interference items. Among Arab individuals with cancer, Nejmi et al. (25) reported high internal consistency of to- tal MDASI $(\alpha=0.85$ ), while $\alpha$ was 0.78 for the symptom severity items and 0.79 for the interference items.

\section{Vitality Subscale of SF-36}

SF-36 is a widely used scale that assesses health and functioning for the last 4 weeks (20). This generic tool is universally valued and is not age, disease or treatment specific. The Vitality Subscale from SF-36 was used to examine convergent validity. The Vitality Subscale comprises 4 items. Subscale scores range from o to 100 with higher scores denoting greater vitality. An internal consistency reliability of 0.87 was found for the tool among a population of 1692 in the United States of America (26). In an Arab general population of 1632 , the internal consistency reliability of the tool was 0.70 (27).

\section{Statistical analysis}

SPSS version 18 was used for data analysis. All data entered were checked for missing data and outliers. Data set was checked using the frequency analysis to ensure that missing data did not exceed $5 \%$ of the total data. In case of missing data that exceeded 3 items for the same participant, the whole data for that participant were removed from the dataset. Outliers in demographic variables were checked using the frequency analysis and histogram. In case of outliers, we referred to the original questionnaire to ensure proper entry. Data analysis was run by calculating descriptive statistics [frequency, percentages, mean and standard deviation (SD)] and inferential statistics (Pearson correlation coefficient). The Pearson correlation coefficient was demonstrated when assessing item-to-total correlation, item-to-item correlations for the BFI-A, and convergent validity between the BFI-A and the Arabic versions of the ISI, ZDS, MDASI and SF-36 Vitality subscale. Cronbach's $\alpha$ was calculated to test the internal consistency reliability of all measured scales. Sample size calculation was based on $G^{*}$ Power 3.0.10 (28) assuming a medium effect size (Pearson $r=0.30), \alpha=0.05$, and power $=0.80$. Based on this equation, the total sample required for a 1-tail test to detect significant correlations for validity comparisons was 67 .

\section{Results}

After explanation of the purpose and objectives of the study, the questionnaire package was given to $100 \mathrm{pa}-$ tients with 79 returning the questionnaire (response rate $=79 \%$ ). The participants' response rate to the BFI items was high, with a missing data rate of $2 \%$ of the total data points. All the collected data were included in the analysis as the majority of the participants responded to at least 5 items in the BFI-A.

Sociodemographic characteristics of the participants are shown in Table 1. Average age was 46 (13.9) years (range $=18-74$ years), $55.7 \%(n=44)$ were female and most were married $(n=65,82.3 \%)$. The average BFI-A total score was 4.0 (2.4) (Table 2), indicating non-severe fatigue. The majority of patients $(83.5 \%)$ had non-severe fatigue (0-6.9), while $16.5 \%$ had severe fatigue (7-10). The BFI intensity mean score was 4.0 (2.6), while BFI interference mean score was 4.1 (2.5). 


\begin{tabular}{|c|c|c|}
\hline \multirow[t]{2}{*}{ Variable } & \multicolumn{2}{|c|}{ Total $(n=79)$} \\
\hline & Mean & SD (range) \\
\hline & $n$ & $\%$ \\
\hline Age (yr) & 46 & $13.9(18-74)$ \\
\hline \multicolumn{3}{|l|}{ Sex } \\
\hline Male & 35 & $44 \cdot 3$ \\
\hline Female & 44 & 55.7 \\
\hline \multicolumn{3}{|l|}{ Marital status } \\
\hline Married & 65 & 82.3 \\
\hline Not married & 14 & 17.7 \\
\hline \multicolumn{3}{|l|}{ Education } \\
\hline Higher than secondary & 44 & 55.6 \\
\hline Up to secondary & 35 & 44.4 \\
\hline \multicolumn{3}{|l|}{ Employment } \\
\hline Employed & 22 & 27.8 \\
\hline Unemployed & 57 & 72.1 \\
\hline \multicolumn{3}{|l|}{ Type of treatment } \\
\hline Chemotherapy & 40 & 50.6 \\
\hline Radiology & 14 & 17.7 \\
\hline Hormones & 5 & 6.3 \\
\hline Others & 20 & 25.3 \\
\hline
\end{tabular}

\begin{tabular}{lcc}
\hline $\begin{array}{l}\text { Table } 2 \text { Brief Fatigue Inventory (BFI-Arabic) total and items } \\
\text { means and SDs }\end{array}$ & Mean & SD \\
\hline BFI items & & \\
Fatigue severity items & 4.1 & 2.7 \\
$\quad$ Fatigue now & 3.9 & 2.9 \\
$\quad$ Fatigue usual & 4.3 & 2.9 \\
$\quad$ Fatigue worst & & \\
Fatigue interference items & 4.0 & 3.1 \\
$\quad$ General activity & 4.4 & 2.9 \\
Mood & 4.0 & 2.9 \\
$\quad$ Walking & 4.1 & 2.9 \\
$\quad$ Work & 3.9 & 3.2 \\
Relations & 4.3 & 3.2 \\
Enjoyment & 4.0 & 2.4 \\
$\quad$ Total BFI (Average of 9 items) &
\end{tabular}

The internal consistency reliability of the BFI-A was estimated by calculating the Cronbach $\alpha$ coefficients. The coefficient was 0.93 for all 9 items, 0.93 for the 3 fatigue severity items and 0.92 for the 6 fatigue interference items, indicating good internal consistency. To further assess the homogeneity of the BFI-A, Pearson correlations among the BFI-A total score and items were calculated (Table 3). The correlations between the BFI-A total score and items were significant and ranged from 0.75 (fatigue now item) to 0.86 (enjoyment item). In addition, the item-to-item correlation coefficients ranged from 0.37 to 0.85 .
The BFI-A total score showed strong positive correlations with total scores of the ISI, MDASI and ZDS (Table 4). A strong negative correlation was found as expected with SF- 36 vitality score. All correlations were > 0.57 , indicating strong convergent validity.

\section{Discussion}

The total score from the BFI is widely used in research studies to examine fatigue severity. The mean total score of the BFI in this study indicates that, on average, the participants had non-severe levels of fatigue. Similar findings were reported in the original BFI English validation study (8) and in other BFI translation studies such as German and Taiwanese $(10,11)$. The BFI-A also demonstrated strong psychometric properties (reliability and validity). These results indicate that the BFI-A can be used to measure fatigue in Arab patients with cancer. All of the participants in the current study were able to respond to the 9 items of the BFI-A. This suggests that the BFI is straightforward, easy to comprehend, and is suitable for different age groups in the recruited sample.

The reliability of the BFI-A was excellent for the overall instrument and for the 3 fatigue severity and 6 fatigue interference items in this sample of cancer outpatients. Similar high reliability values were reported for other translation studies. All the translation studies reported reliability values $>0.90$, ranging from 0.92 for the German (10) and Chinese (5) versions to 0.96 for the Japanese (2) and Taiwanese (11) versions.

Similar to the current study, it appears that earlier researchers found high internal consistency reliability in cancer patients. Testing of the internal homogeneity of the BFI-A in the current study revealed high item-tototal and item-to-item correlations. The correlations in the current study are supported by similar correlations in earlier studies. For example, the Greek validation study (9) reported significant correlations between the BFI items ranging from 0.57 to 0.88 , while the Taiwanese validation study (11) reported significant correlations between the BFI items ranging from 0.60 to 0.93 .

Convergent validity evidence was provided for the total BFI score. The total score correlated highly with the MDASI total score. The Greek validation study (9) also reported a strong positive correlation between the total BFI and total MDASI scores.

The high correlation between the BFI-A and MDASI in the current study was probably because the MDASI by itself measures 13 core symptoms, including fatigue, in addition to the 6-symptom interference scale with the same scoring method as the BFI. This suggests that fatigue is a sentinel symptom that, when severe, is associated with multiple, co-occurring symptoms.

Likewise, the total BFI in the current study demonstrated a moderate negative correlation with the SF-36 Vitality Subscale. The Chinese validation study (5) found stronger correlations than the current study between the BFI and the SF-36 Vitality Subscale among 


\begin{tabular}{|c|c|c|c|c|c|c|c|c|c|c|}
\hline BFI items & $\begin{array}{c}\text { Global } \\
\text { BFI }\end{array}$ & FN & FU & FW & GA & $\mathbf{M}$ & WA & Wo & $\mathbf{R}$ & $E$ \\
\hline Global BFI & 1 & $0.81^{* *}$ & $0.75^{* *}$ & $0.79^{* *}$ & $0.83^{* *}$ & $0.84^{* *}$ & $0.78^{* *}$ & $0.82^{* *}$ & $0.77^{* *}$ & $0.86^{* *}$ \\
\hline Fatigue now (FN) & & 1 & $0.79^{* *}$ & $0.83^{* *}$ & $0.56^{* *}$ & $0.61^{* *}$ & $0.47^{* *}$ & $0.52^{* *}$ & $0.48^{* *}$ & $0.65^{* *}$ \\
\hline Fatigue usual (FU) & & & 1 & $0.85^{* *}$ & $0.59^{* *}$ & $0.54^{* *}$ & $0.52^{* *}$ & $0.47^{* *}$ & $0.37^{* *}$ & $0.45^{* *}$ \\
\hline Fatigue worst (FW) & & & & 1 & $0.62^{* *}$ & $0.59^{* *}$ & $0.48^{* *}$ & $0.45^{* *}$ & $0.45^{* *}$ & $0.52^{* *}$ \\
\hline General activity (GA) & & & & & 1 & $0.64^{* *}$ & $0.69^{* *}$ & $0.75^{* *}$ & $0.51^{* *}$ & $0.64^{* *}$ \\
\hline Mood (M) & & & & & & 1 & $0.59^{* *}$ & $0.62^{* *}$ & $0.73^{* *}$ & $0.75^{* *}$ \\
\hline Walking (WA) & & & & & & & 1 & $0.77^{* *}$ & $0.59^{* *}$ & $0.58^{* *}$ \\
\hline Work (WO) & & & & & & & & 1 & $0.60^{* *}$ & $0.67^{* *}$ \\
\hline Relations (R) & & & & & & & & & 1 & $0.76^{* *}$ \\
\hline Enjoyment (E) & & & & & & & & & & 1 \\
\hline
\end{tabular}

${ }^{*} \mathrm{P}<0.05 ;{ }^{* *} \mathrm{P}<0.01 . \mathrm{BFI}=$ Brief Fatigue Inventory.

patients with cancer. The Chinese validation study (5) recruited both outpatients and inpatients, which is probably responsible for the strong correlation in patients having different treatment in addition to hospitalization, which is a stressful situation for the patients. The Japanese validation study (2) found a strong significant relationship between the BFI and Fatigue Subscale from the Profile of Mood States and the Fatigue Subscale from the European Organization for Research and Treatment of Cancer QLQ 30 among Japanese patients with cancer.

In the current study, the BFI-A demonstrated a high positive correlation with the ISI. None of the prior BFI translation studies examined this relationship. However, other researchers reported significant positive correlation between fatigue and sleep disturbances among 715 patients with cancer (29), which supports the results of the current study. Another significant correlation in the current study was found between the BFI-A and ZDS. None of the prior studies that translated the BFI used the ZDS for validity purposes. However, Hwang et al. (30) reported a strong negative correlation between BFI and ZDS among 180 patients with different cancer diagnoses.

Although our study used many scales to test the BFI convergent validity, there were some limitations. Data were collected from outpatients who visited the clinics. Hospitalized patients were not included. It would be useful to include a large sample of hospitalized patients in future studies. Alarge sample size will allow us to assess fatigue in different demographic groups. Also, discriminant validity, test-retest reliability or factor analysis was not conducted
Table 4 Brief Fatigue Inventory (BFI-Arabic) totala and items means and SDs

\begin{tabular}{lcc}
$\begin{array}{l}\text { Comparison } \\
\text { instrument }\end{array}$ & \multicolumn{2}{c}{ BFI-Arabic } \\
& $\begin{array}{c}\text { Pearson } \\
\text { correlation } \\
\text { coefficient }\end{array}$ & P \\
\hline MDASI total score & 0.75 & $<0.001$ \\
ISI total & 0.70 & $<0.001$ \\
ZDS total & 0.69 & $<0.001$ \\
SF-36 Vitality subscale & -0.57 & $<0.001$ \\
\hline
\end{tabular}

BFI = Brief Fatigue Inventory; ISI = Insomnia Severity Index; $M D A S I=M . D$. Anderson Symptom Inventory; SF-36 = Medical Outcomes Study Short-Form 36; ZDS = Zung Depression Scale.

for the Arabic BFI. Future studies should collect data on type, stage and duration of cancer to determine whether patients with various types and later stages of cancer requiring longer treatment would have more fatigue than patients in earlier stages with shorter treatment.

In summary, the BFI has been translated into Arabic and demonstrated excellent internal consistency reliability and good convergent validity in this sample. This makes it a useful tool for use in research that examines interventions to manage fatigue among Arab patients with cancer in clinical settings. The Arabic BFI may also allow cross-cultural comparison with other countries to improve the management of fatigue among patients with cancer.

Funding: None.

Competing interests: None declared. 


\section{Étude de validation de la version arabe du Brief Fatigue Inventory (BFI-A) \\ Résumé}

Contexte : La fatigue est le symptôme le plus fréquent et le plus éprouvant chez les patients atteints de cancer. Cependant, aucun questionnaire mesurant la fatigue et son interférence avec la vie quotidienne n'a été traduit en arabe.

Objectif : La présente étude visait à traduire et à valider la version arabe du Brief Fatigue Inventory (BFI-A).

Méthodes : Le BFI a été traduit en arabe à l'aide de la technique de traduction/rétro-traduction. La présente étude transversale a permis de collecter des données de patients atteints de cancer en recourant à un auto-questionnaire comprenant le BFI-A, l'index de Sévérité de l'Insomnie (ISI), l'échelle d'auto-évaluation de la dépression de Zung (ZDS), l'inventaire des symptômes M.D. Anderson (MDASI) et la sous-échelle vitalité de la forme abrégée du questionnaire généraliste SF-36 (qualité de vie) du Medical Outcome Study. Des statistiques descriptives et inférentielles ont été utilisées, y compris la moyenne, l'écart type, la cohérence interne et le coefficient de corrélation de Pearson.

Résultats: 79 patients au total ont été recrutés à Amman (Jordanie) en 2015. La moyenne totale du BFI-A était de $4,01(2,4)$, indiquant que $83,5 \%$ des patients présentaient un état de fatigue non sévère. Le coefficient alpha de Cronbach du BFI-A était de 0,93. Les corrélations entre les scores totaux et les rubriques du BFI-A étaient significatives $(p<0,05)$ et étaient comprises entre 0,75 et 0,86 . Le BFI-A affichait une corrélation importante $(p<0,05)$ avec les instruments suivants : ISI = 0,70; ZDS = 0,69; MDASI = 0,75 et la sous-échelle vitalité du SF-36 (qualité de vie) = -0,57.

Conclusion : La présente étude suggère que le BFI-A est un outil valable et fiable pour évaluer la fatigue chez les patients arabes atteints de cancer.

$$
\begin{aligned}
& \text { دراسة للتحقق من النسخة العربية لمقياس التعب الوجيز (BFI-A) } \\
& \text { خالد سليمان، محمود الكلالدة، لؤي أبو شحرور، برنيس ييتس، آن بيرجر، تيتو مندوزا، ملكة ملك، أيمن بني سلامة، شارلز كليلاند، أحمد المنشاوي } \\
& \text { الخلفية: يُعدّ التعب أكثر الأعر اض التي يشكو منها مرضى السرطان و أكثرها تكديراً لهم. ومع ذلك، لمُ يُّترجم إلى اللغة العربية أي استبيان يقيس }
\end{aligned}
$$

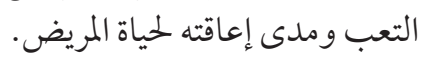

$$
\begin{aligned}
& \text { الأهداف: كانت هذه الدراسة تهدف إلى ترجمة "مقياس التعب الوجيز" (BFI-A) و التحقق من نسخته العربية. }
\end{aligned}
$$

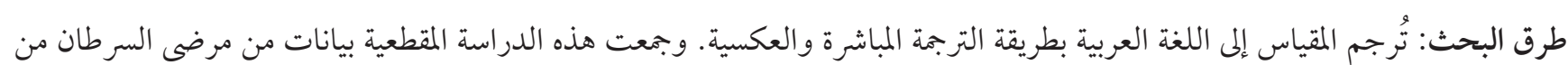

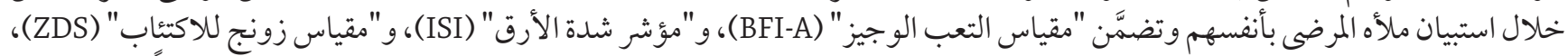

\section{References}

1. Cruz FM, Munhoz BA, Alves BC, Gehrke FS, Fonseca FL, Kuniyoshi RK, et al. Biomarkers of fatigue related to adjuvant chemotherapy for breast cancer: evaluation of plasma and lymphocyte expression. Clin Transl Med. 2015 Feb 14;4:4. http://dx.doi. org/10.1186/s40169-015-0051-8 PMID:25852820

2. Okuyama T, Wang XS, Akechi T, Mendoza TR, Hosaka T, Cleeland CS, et al. Validation study of the Japanese version of The Brief Fatigue Inventory. J Pain Symptom Manage. 2003 Feb;25(2):106-17. http://dx.doi.org/10.1016/So885-3924(02)00596-1 PMID:12590026

3. Catania G, Bell C, Ottonelli S, Marchetti M, Bryce J, Grossi A, et al. Cancer-related fatigue in italian cancer patients: validation of the Italian Version of The Brief Fatigue Inventory (BFI). Support Care Cancer. 2013 Feb;21(2):413-9. http://dx.doi.org/10.1007/ s00520-012-1539-z PMID:22790224

4. Network NCC. Cancer-Related Fatigue 2016 [cited 2016 June 8th]. Available from: (https://www.nccn.org/patients/resources/ life_with_cancer/managing_symptoms/fatigue.aspx). 
5. Wang XS, Hao XS, Wang Y, Guo H, Jiang YQ, Mendoza TR, et al. Validation study of the Chinese version of The Brief Fatigue Inventory (BFI-C). J Pain Symptom Manage. 2004 Apr;27(4):322-32. http://dx.doi.org/10.1016/j.jpainsymman.2003.09.008 PMID:15050660

6. Denieffe S, Cowman S, Gooney M. Symptoms, Clusters and quality of life prior to surgery for breast cancer. J Clin Nurs. 2014;23(17-18):2491-502. http://dx.doi.org/ 10.1111/jocn.12430.

7. Yun YH, Wang XS, Lee JS, Roh JW, Lee CG, Lee WS, et al. Validation study of the korean version of the brief fatigue inventory. J Pain Symptom Manage. 2005 Feb;29(2):165-72. http://dx.doi.org/10.1016/j.jpainsymman.2004.04.013 PMID:15733808

8. Mendoza TR, Wang XS, Cleeland CS, Morrissey M, Johnson BA, Wendt JK, et al. The rapid assessment of fatigue severity in cancer patients: use of The Brief Fatigue Inventory. Cancer. 1999 Mar 1;85(5):1186-96. http://dx.doi.org/10.1002/(SICI)10970142(19990301)85:5<1186::AID-CNCR24>3.0.CO;2-N PMID:10091805

9. Mystakidou K, Tsilika E, Parpa E, Mendoza TR, Pistevou-Gombaki K, Vlahos L, et al. Psychometric properties of the Brief Fatigue Inventory in Greek patients with advanced cancer. J Pain Symptom Manage. 2008 Oct;36(4):367-73. http://dx.doi.org/10.1016/j. jpainsymman.2007.10.021 PMID:18440770

10. Radbruch L, Sabatowski R, Elsner F, Everts J, Mendoza T, Cleeland C. Validation of the German version of The Brief Fatigue Inventory. J Pain Symptom Manage. 2003May;25(5):449-58. http://dx.doi.org/10.1016/So885-3924(03)00073-3PMID:12727043

11. Lin C, Chang A, Chen M, Cleeland C, Mendoza T, Wang X. Validation study of the Taiwanese version of the Brief Fatigue Inventory. J Pain Symptom Manage. 2006 Jul;32(1):52-9. http://dx.doi.org/10.1016/j.jpainsymman.2005.12.019 PMID:16824985

12. Brislin R. Back-translation for cross-cultural research. J Cross Cult Psychol 1970 Sep 1;1(3):185-216. http://dx.doi. org/10.1177/135910457000100301

13. Chalder T, Berelowitz G, Pawlikowska T, Watts L, Wessely S, Wright D, et al. Development of a fatigue scale. J Psychosom Res. 1993;37(2):147-53. http://dx.doi.org/10.1016/0022-3999(93)90081-P PMID:8463991

14. Mcllvenny S, Ahmed MH, E. D, Swadi H, Balshie M. The Translation into Arabic and Revalidation of a Fatigue Questionnaire. East Mediterr Health J. 1999 May;5(3):503-14. PMID:10793829

15. McIlvenny S, DeGlume A, Elewa M, Fernandez O, Dormer P. Factors associated with fatigue in a family medicine clinic in the United Arab Emirates. Fam Pract. 2000 Oct; 17(5):408-13. http://dx.doi.org/10.1093/fampra/17.5.408 PMID:11021901

16. Su CT, Parham LD. Generating a Valid Questionnaire Translation for Cross-Cultural Use. Am J Occup Ther. 2002 SepOct;56(5):581-5. PMID:12269514

17. Morin C. Insomnia: psychological assessment and management. New York: Guilford Press; 1993.

18. Zung W. A self-rating depression scale. Arch Gen Psychiatry 1965 Jan;12(1):63-70. http://dx.doi.org/10.1001/archpsyc.1965.01720310065008 PMID:14221692

19. Cleeland CS, Mendoza TR, Wang XS, Chou C, Harle MT, Morrissey M, et al. Assessing symptom distress in cancer patients: the M.D. Anderson Symptom Inventory. Cancer. 2000 Oct 1;89(7):1634-46. http://dx.doi.org/10.1002/10970142(20001001)89:7<1634::AID-CNCR29>3.0.CO;2-V PMID:11013380

20. Ware J, Snow K, Kosinski M, Gandek B. SF-36 Health Survey: manual \& interpretation. Boston: New Medical Center; 1993.

21. Bastien C, Vallieres A, Morin C. Validation of the Insomnia Severity Index as an outcome measure for insomnia research. Sleep Med. 2001 Jul;2(4):297-307. http://dx.doi.org/10.1016/S1389-9457(00)00065-4 PMID:11438246

22. Suleiman K, Yates B. Translating the Insomnia Severity Index into Arabic. J Nurs Scholarsh. 2011 Mar;43(1):49-53. http://dx.doi. org/10.1111/j.1547-5069.2010.01374.x PMID:21342424

23. De Jonghe JF, Baneke JJ. The Zung Self-Rating Depression Scale: a replication study on reliability, validity and prediction. Psychol Rep. 1989 Jun 1;64(3):833-4. http://dx.doi.org/10.2466/pro.1989.64.3.833.

24. Kirkby R, Al Saif A, El-din Mohamed G. Validation of an Arabic Translation of The Zung Self-Rating Depression Scale. Ann Saudi Med. 2005 May-Jun;25(3):205-8. http://dx.doi.org/10.5144/0256-4947.2005.205 PMID:16119520

25. Nejmi M, Wang XS, Mendoza TR, Gning I, Cleeland CS. Validation and application of the Arabic version of The M. D. Anderson Symptom Inventory in Moroccan patients with cancer. J Pain Symptom Manage. 2010 Jul;40(1):75-86. http://dx.doi.org/ 10.1016/j. jpainsymman.2009.12.007 PMID:20619213

26. McHorney CA, Kosinski M, Ware JE, Jr. Comparisons of the costs and quality of norms for the SF-36 health survey collected by mail versus telephone interview: results from a national survey. Med Care. 1994 Jun;32(6):551-67. PMID:8189774

27. Sabbah I, Drouby N, Sabbah S, Retel-Rude N, Mercier M. Quality of life in rural and urban populations in Lebanon using SF 36 Health Survey. Health Qual Life Outcomes 2003 Aug 6;1:30. http://dx.doi.org/10.1186/1477-7525-1-30 PMID:12952543

28. Faul F, Erdfelder E, Lang AG, Buchner A. G*Power 3: a flexible statistical power analysis program for the social, behavioral, and biomedical sciences. Behav Res Methods. 2007 May;39(2):175-91. http://dx.doi.org/ 10.3758/bfo3193146 PMID:17695343

29. Davis MP, Khoshknabi D, Walsh D, Lagman R, Platt A. Insomnia in patients with advanced cancer. Am J Hosp Palliat Care. 2014 Jun;31(4):365-73. http://dx.doi.org/ 10.1177/1049909113485804 PMID:23616275

30. Hwang SS, Chang VT, Kasimis BS. A comparison of Three Fatigue Measures in Veterans with Cancer. Cancer Invest. 2003 Jun;21(3):363-73. http://dx.doi.org/10.1081/CNV-120018227 PMID:12901282 